\title{
HARVEST - THE WEEK BEFORE AND ON THE DAY
}

\author{
G. Marr
}

The first rule in harvesting is not to panic. The second is to plan ahead and prepare the machinery months in advance so that everything is ready when the time comes. As a general rule when the cocksfoot crop flowers at Methven there are 28 days until harvest; when close examination of the seed kernel indicates that it has passed from the milk to dough stage, there are seven days. left.

Cocksfoot is judged to be ripe when seed drops into a hat swept through the crop. If in doubt an infra-red lamp is used. After cutting, the crop is windrowed high, parallel to the prevailing wind. A secondary cut with the rotary mower increases wind protection and improves ease of pickup.

Bad weather at harvest time is extremely worrying. Old and sound advice is to convert worry into a problem and solve it. As weather is uncontrollable and cannot be solved, there is no point in worrying about it. Instead use the time to carry out machine maintenance.

If bad weather is forecast the grower must make the decision to cut, combine or leave the crop. The long-range weather forecast, broadcast at $16.00 \mathrm{~h}$ daily, can be of assistance in the decision. Stationary weather systems should be treated with extreme caution. If the stationary system is bad weather, crops on the ground will be extremely vulnerable.

Thrashing generally follows three to four days after cutting, when seed moisture is at $20 \%$. Whether an axial flow or conventional harvester is used depends entirely upon farmer preference and experience. In thrashing cocksfoot one to two percent of the seed in a sample should be hulled. At this level awns will be left on weed seeds, rendering them extractable. If seed in the sample is unthrashed the concave should be opened or drum speed increased.

In a bulk seed-handling system seed can be dried and dressed by the bin load. A recommended system is to record the temperature of each seed load plus size and time of unloading.. If these details are noted the priority of cooling will be known. Three quarters of an hour with fan cooling is generally sufficient to render the seed safe for short term storage and prevent damage to viability. Final cooling can be done on a north-easterly day. Although seed is considered to be safe in bags, it is even safer in bins. It must, however, be monitored constantly in order to avoid damage. For instance, seed put into the bin at $25^{\circ} \mathrm{C}$ increases in temperature over a period of seven to ten days unless cooled., The increase in temperature may result in decreased viability. 
During the harvesting process extreme care must be taken in order to avoid contamination between different crops. The best method is keep seeds entirely separate, i.e., different machinery and storage places. If that is not possible, thorough cleaning is vital. Air compressors and high pressure hoses can be used to blow seed out of machinery but it must be remembered that seed blown out must go somewhere, therefore a vacuum is more efficient.

\title{
IS YOUR PASTURE PERFORMING POORLY?
}

\section{It is important that you make the right decisions when regrassing.}

\author{
Were you aware that :
}

- There are over 30 pasture varieties now available to improve your farm production and flexibility.

- Your farm is a unique enterprise, each paddock requiring individual pasture varieties 'and management.

- Correct establishment and management of your new pastures will result in higher profitability for many years.

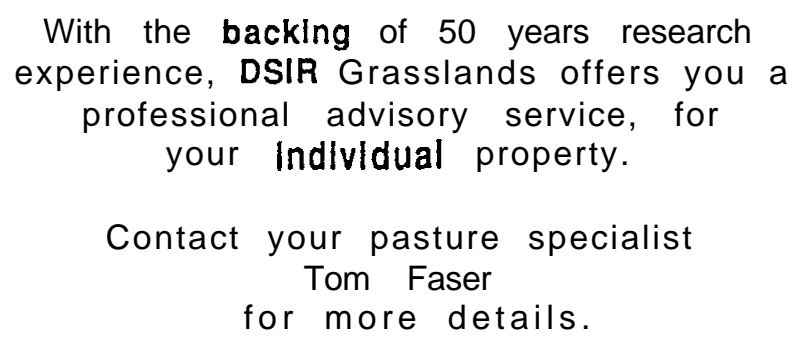

Phone (03) 252-511, After-Hours (03) 252-473

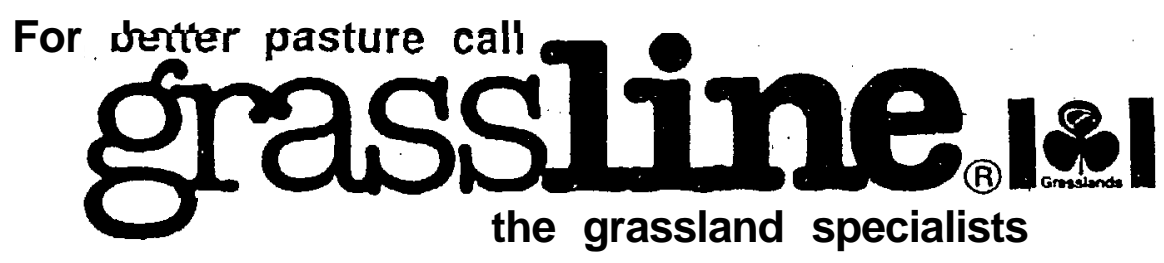

